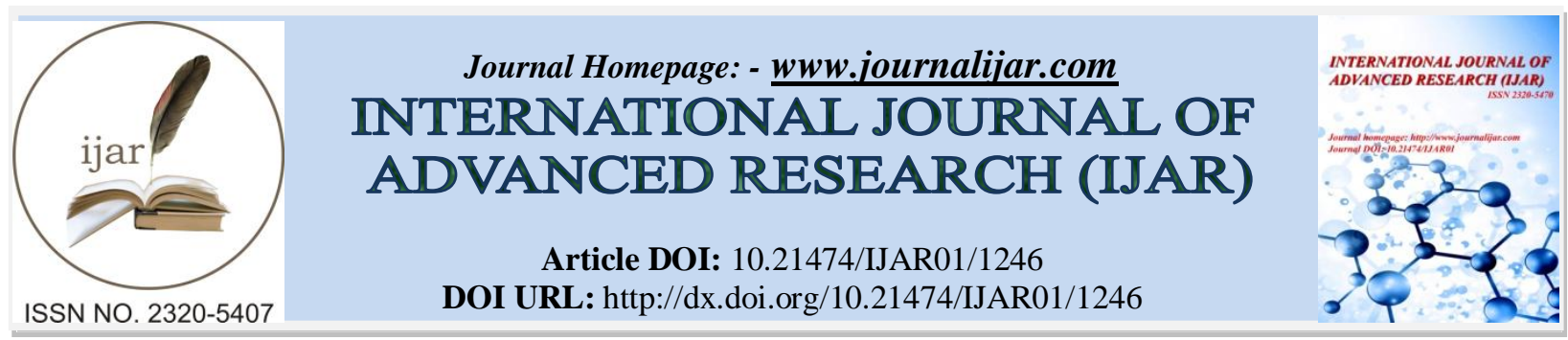

RESEARCH ARTICLE

\title{
COMPREHENSIVE FRAMEWORK FOR SCHOOL DROPOUT PREDICTION AND PREVENTION: A CASE STUDY OF SCHOOL DROPOUTS IN RURAL AREAS OF MAHBUBNAGAR DISTRICT OF TELANGANA.
}

Deepak Kumar Dey.

Ph.D Scholar, Faculty of Education and Arts, Jodhpur National University, Rajasthan, India.

\section{Manuscript Info}

Manuscript History

Received: 19 June 2016

Final Accepted: 11 July 2016

Published: August 2016

Key words:-

School Dropouts, Prediction,

Framework, Education, Social

Protection, and Parent's Attitude.

\section{Abstract}

Obtaining quality education is non-negotiable to improve people's lives. It is fundamental human right and essential for the empowerment and growth. Despite numerous actions for realization of mission 'Education for All', however, have been reported high rate of school dropouts in Telangana state and India as well. In 2013-14, about 38.2 per cent of children in the state of Telangana in India who had enrolled in Class I did not reach Class X, thus deprived of schooling.

Various studies informed that the negative outcomes of school dropouts for individuals are related to one another and that their causes and the backgrounds of dropouts are knotted. By addressing the signs of school dropouts, not only will students stay in school, but also future problem behaviors could be avoided.

This paper attempted to design result framework, comprehensive school dropout prediction framework comprised of seven domains include personal attributes, academic learnings, general deviance, deviant affiliation, family socialization, structural strains and child friendly school environment. At the end of the paper, author also developed self-rating instrument for school management committee and class teacher to use and predict possibilities of school dropouts in their class and reinforce to develop child specific plan of action for ensuring accomplishment of schooling. It is recommended to design series of robust programs to tap capacity gaps among children, families, communities, school functionaries and district officials and improve individual and collective behavioral issues and performance at the institutional level.

\section{Introduction:-}

Obtaining quality education is non-negotiable to improve people's lives. It is fundamental human right and essential for the empowerment and growth. It is also clearly articulated in the fourth goal of United Nations Sustainable Development Agenda 2030 that every nations shall ensure inclusive and quality education for all and promote lifelong learning. Right to Education is being implemented in India. Despite numerous actions for realization of 
mission 'Education for All', however, have been reported high rate of school dropouts in Telangana state and India as well.

As per State Project Director, Rajiv Vidhya Mission (SSA), Education Statistics report of Telangana State, India in 2013-2014, Page 71, It was found that Mahbubnagar district of Telangana state has topped (53.2 per cent) of school dropout in Telangana state; about 38.2 per cent of children in the state who had enrolled in Class I did not reach Class X, thus deprived of basic education.

Various studies informed that the negative outcomes of school dropouts for individuals are related to one another and that their causes and the backgrounds of dropouts are knotted. By addressing the signs of school dropouts, not only will students stay in school, but also future problem behaviors could be avoided. This study (Dey, 2016) indicates that parents of the school dropouts were more vulnerable and prone to economic centric issues. However, not all parents may be behaving in the same manner to economic centric issues when it comes to. Similarly, school environment is universal to all children but not all children drops out. This indicates that though economic centric and school centric issues are universal and more common, there are parent centric and child centric factors which influences the critical decision in dropping out (Dey, 2016).

Positioning the above context to the analysis derived from the study it clearly indicates that socio-economic strains play a major role in decision making; however, they are linked to child centric and school centric issues. Hence, it may be appropriate to plot that across the universal presence of economic and school centric issues, any occurrence of events/ factors in parent and child centric dimension would be the final nail in deciding on the school dropouts.

This paper aims to design evidence based comprehensive school dropout prediction framework so that appropriate preventive and protective programs could be designed to tag capacity gaps of children, families, communities, school functionaries and district officials to improve individual and collective behavioral issues and performance at the institutional level.

\section{Materials and methods:-}

One of the objectives of author's $\mathrm{PhD}$ is to design comprehensive framework for dropout predictions and assessing intervention points. This paper is the outcome of the study that was confined to 401 families where dropouts in their home was existed covering 18 villages and six Mandals (administrative unit) of Mahbubnagar district, Telangana State.

The study applied three research designs; survey design, cross sectional design and explorative design. Mandal-wise drop-out in the age group 6-18 years in Mahbubnagar district during 2013-14 was provided by Education Department of Telangana State. Researcher has applied rural Mandal-wise dropout details as sample frame. Using circular systematic random sampling, six Mandals and 18 villages were selected. Almost 100 per cent households were selected where school dropout cases were found.

Using theory of social disorganization (Battin-Pearson et at., 2000) as base framework and added evidence based indicators from the literature reviews, a comprehensive research instrument was prepared that include variables like parent's learning, school environment, parents-teacher relationship, parents involvement, structural strains, academic mediation, poor family socialization, general deviance and deviant affiliation. The reliability coefficient (Cronbach's Alpha) of fifty-four items is 0.84 , which lies above the threshold of 0.70

The suggested comprehensive school dropout prediction framework was developed based on above indicators and would be helpful to predict possibilities of school dropouts of children enrolled in the school by the school management committee so that appropriate preventive, and protective actions could be designed to tag capacity gaps at supply side (department), demand side (community), and enabling environment (policy) leading to improve behavioural changes and/or performance at institutional level and rights holders' level.

\section{Results and discussion:-}

Prediction of dropout possibilities at school would be useful to prepare child specific plans to mitigate the basic issues. By addressing the precursors of dropout at school, not only will student stay in school, but also prevent from the wastage of huge resources. The prediction framework is designed and developed based on the evidences being 
generated from published data as well as primary data around socio-economic backgrounds of dropout families, their attitudes towards school dropouts, causative factors, and reasons of school dropouts. Following are the summary details given.

\section{Socio-Economic Status of Dropout Families:-}

According to this study (Dey, 2016) showed that majority of the parents of the school dropout children are belongs to Hindu religion (91 per cent); backward caste (49 per cent), schedule caste (39 per cent); had kutcha (20 per cent) and Semi-Pucca houses (33 per cent); association with Self Help Groups ( 80 per cent) and family income below INR 78,000 per annum and majorities were holding below poverty line (BPL) cards. The parents are also frequently migrating and 80 per cent are illiterate and dependent on social protection programmes of government (Dey, 2016).

\section{Parent's Attitude towards School Dropouts:-}

According to this study (Dey, 2016) showed that parent's attitude towards learning (PATL), children who dropped out (REASONS), parent's involvement (PI), parents-teachers relationships (PTR), and parent's attitude towards school environment (PATSENV) are key factors associated to school dropouts. Following are the summary of statistical significance of various factors.

Table 1:- Summary of Statistical Significance.

\begin{tabular}{|l|l|l|l|l|l|}
\hline S.no. & \multirow{2}{*}{ Factors } & Statistical Significant $(\mathbf{p}<\mathbf{. 0 5})$ & \multicolumn{2}{l|}{} \\
\cline { 3 - 6 } & & Social Group & Religion & SHG Memberships & Income \\
\hline 1 & Learning & Yes & No & Yes & No \\
\hline 2 & Parents Involvement & Yes & No & No & Yes \\
\hline 3 & Parents-Teachers relationship & Yes & Yes & No & Yes \\
\hline 4 & School environment & Yes & Yes & No & No \\
\hline 5 & Delinquency & Yes & No & No & Yes \\
\hline 6 & Peer group influence & No & Yes & Yes & Yes \\
\hline
\end{tabular}

The pattern emerging from Table 1 revealed that social group is associated with all factors of dropouts except peer group influence; religion is only associated with parent-teacher relationship, school environment and peer group influence. The SHG membership of parents are associated with learnings, and peer group influence. However, income is associated with parent's involvement, parent-teacher relationship, delinquency and peer group influence (Dey, 2016).

\section{Causative Factors towards Dropouts:-}

According to this study (Dey, 2016) that using partial correlation analysis, it is revealed that parent-teacher relationship is independent of religion, when income is moderate; parents-teacher relationship is independent of income, when social group is schedule caste; parent-teacher relationships is independent of social group, when income is low and parent's involvement is independent of social group when income is low. Lastly, parent's involvement is independent of 'income' when Social Group is 'backward caste'.

\section{Comprehensive Framework for School Dropout Prediction and Prevention:-}

Capitalising on recent progressive measures ensuring the right to quality education and protection for children, it is important for government and other key stakeholders to ensure availability of cutting edge technical support to schools and community to perform and ensure systems are able to deliver education and social protection services and at the same time, communities are empowered to demand these essential services. Ultimately, the aim is for children to thrive in a child-friendly learning and home environment with strong school, family and community based structures. Embedded in this, influencing positive social values, norms and practices that lead to the equitable utilisation of education and social protection services will be key, as will the generation of robust data.

According to this study (Hunt Frances, 2008) that if processes and risk zones are known then critical predictions and intervention points can be identified before drop out occurs. The paper has benefited from the feedbacks of dropout children, their parents, community members, school teachers to identify critical factors leading to dropouts. Combining grassroots realities, researcher's professional experience and literature reviews, author had developed result framework (Figure 1) for promoting child-friendly environment by the school management committees. 


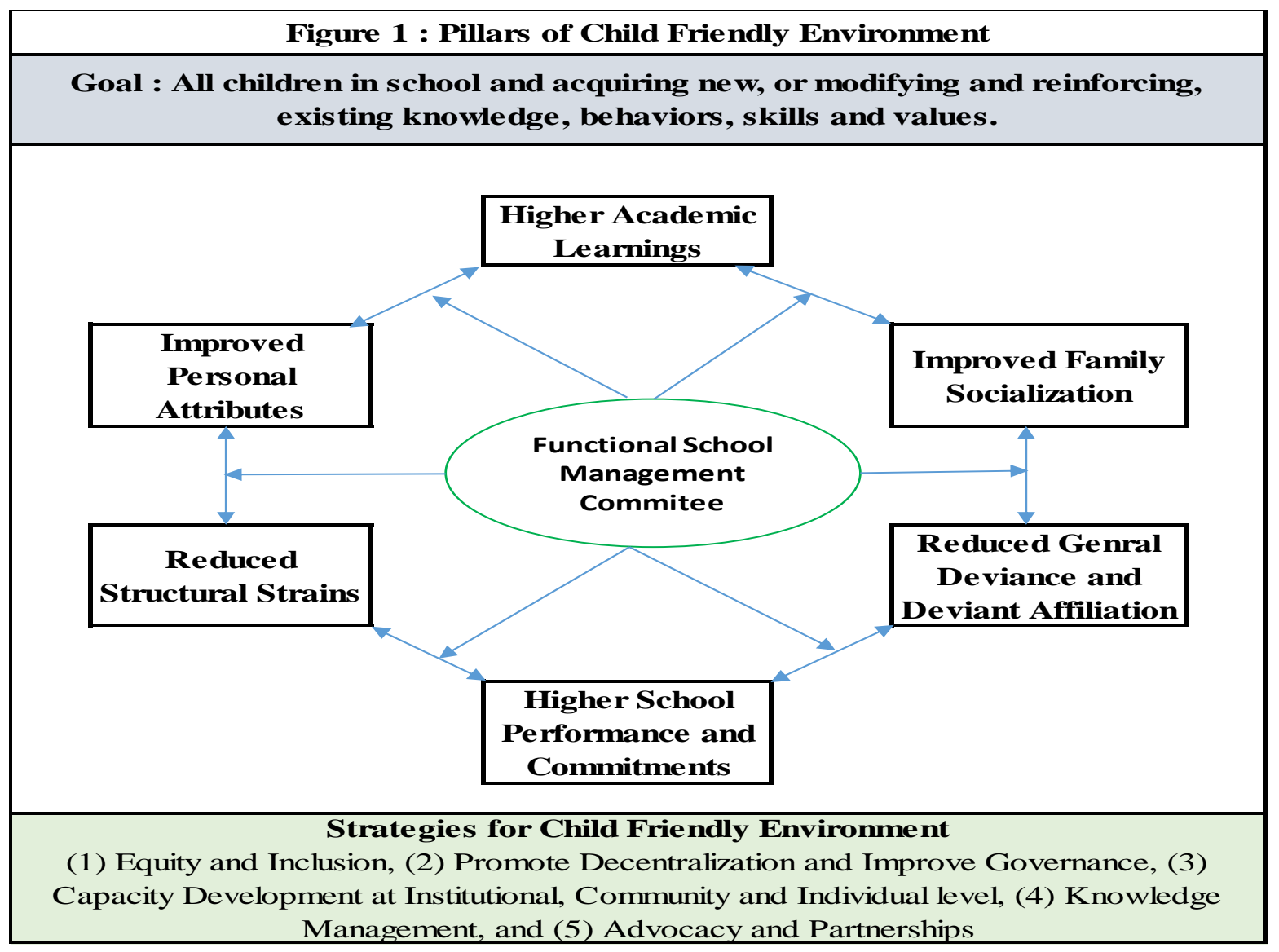

Based on figure 1, comprehensive school dropout framework consists of seven domains and 43 indicators is developed by the author to predict and identify school dropout children:

Personal attributes of Child:- It was observed from the primary data collection by the author that personal attributes of child is one of the predictors of school dropout. Essentially, it looks at how social or personal attributes interacts with and affects the relationship between academic interest and other factors. Following are the suggested indicators under this domain.

a. Can demonstrates caring of others

b. Maintains neatness and hygiene

c. Appearances of politeness to others

d. Shows care of belongings

e. Demonstrates self-initiatives in the school

f. Regularity and punctuality in school affairs

g. Participates in music or arts \& crafts or dance or sports activity

\section{Academic learnings:-}

Research has shown that poor academic achievement is one of the strongest predictors of high school dropout. Essentially, it looks at how poor academic achievement interacts with and affects the relationship between early high school dropout and other factors. Following are the suggested indicators under this domain.

a. Ability to read their class books from language book

b. Ability to write words from language book

c. Ability to articulate sentences from language book

d. Ability to do basic arithmetic calculations from the syllabus

e. Ability to understand / comprehend lessons 


\section{General deviance:-}

Deviant behaviour includes delinquency and early pregnancy. There is a very strong relationship as general deviance is a strong direct predictor of dropout beyond the effect mediated by poor academic achievement. Following are the suggested indicators under this domain.

a. Frequent health issues / disability

b. Violations of codes of conduct

c. Usages of drug / related items

d. Performed or strong possibilities to marry before 18 years

e. Any incidence of elope in the past

\section{Deviant affiliation:-}

The relationship between an individual bonding with antisocial peers and its effect on dropout rates. Students receive the classification of antisocial if they are likely to drop out themselves and/or have low school attachment. If an individual has antisocial friends, he/she is much more likely to drop out of school regardless of how well he/she is doing in school. Following are the suggested indicators under this domain.

a. Violation of codified laws, rules, regulations

b. Students receive the classification/image of anti-social in the community/school

c. Child has antisocial friends

\section{Family socialization:-}

The institution of family appears to very formative for a developing child. The relationship between family background and dropout rates. The relationship is not particularly strong, as academic achievement has much more of an influence than poor family socialization. Factors of poor family socialization include low parental expectations and a parent's lack of education. Following are the suggested indicators under this domain.

a. Education of mother

b. Participation of parents in the school affairs

c. Occupation of the father as daily wage earner

d. Occupation of the mother as daily wage earner

e. Supportive supervision by parents at home

f. Issues in parenting (beating children / beating each other / liquor)

g. Culture \& social beliefs - fear of elope, no matching groom, distance fear

\section{Structural strains:-}

This includes the relationship between demographic factors, such as socioeconomic status, gender and social groups, and dropout. Boys are much more likely to drop out than girls and dropouts are most likely from a family with a low socioeconomic status. Following are the suggested indicators under this domain.

a. Belong to Backward caste/tribes/primitive tribes

b. Family economic base

c. Parents aspiration for the child

d. Membership in SHG or community institutions

e. Child experienced migration or incidence of distress migration in the family

f. Child's involvement in one/other forms of income generating activities

\section{School environment:-}

A school may be labeled "effective" based on student achievement and still not meet the needs of all of its students. Schools that place too much emphasis on achievement alone as a means of being "effective" may alienate their lower achieving students or force them out of school (Wehlage \& Rutter, 1986).

It can also be observed that teachers and schools are not very well prepared for educational partnership. School environment, school structure and management practices influences parents' and teachers' ideas about parental involvement and forms of partnership. Following are the suggested indicators under this domain.

a. Class teacher is able to reach out to child

b. Class teacher's presence in the class (regularity)

c. Class teacher's interest on teaching (effectiveness) 
d. Class teacher's interest on student

e. Class teacher encourage participation of child to cultural activities (if any)

f. Child experiencing corporal punishment (in last one month)

g. Child love school building

h. Attendance of the child in class

i. Location of school

j. Advice or follow up from school management committee (regular meetings, home visits, participating in school activities, management of school development funds)

k. Functioning of infrastructure including facilitates (toilets)

Based on the above, the author has developed simplified self-assessment rating instrument for government schools covering seven domains for each child for a class. The instrument could be administered jointly by the school management committee (SMC) and the class teacher.

Table 2 : Dropout Prediction Instrument

\begin{tabular}{|c|c|c|c|c|c|c|c|c|c|c|}
\hline \multirow[b]{2}{*}{ Sl.No. } & \multirow[b]{2}{*}{ Name of the child } & \multicolumn{7}{|c|}{ Select Scale : Strongly Disagree (1), Disagree (2), Neutral (3), Agree (4), Strongly Agree (5) } & \multirow{2}{*}{$\begin{array}{c}\text { Total } \\
(\text { sum of } \\
\text { column } 3 \text { to } 9)\end{array}$} & \multirow{2}{*}{$\begin{array}{c}\text { Rating } \\
\text { Red/ } \\
\text { Yellow/ } \\
\text { Greem }\end{array}$} \\
\hline & & $\begin{array}{c}\text { Positive } \\
\text { personal } \\
\text { attributes } \\
\quad(1-5)\end{array}$ & $\begin{array}{c}\text { Positive signs } \\
\text { of academic } \\
\text { learnings } \\
(1-5)\end{array}$ & $\begin{array}{c}\text { No signs of } \\
\text { general } \\
\text { deviance } \\
(1-5)\end{array}$ & $\begin{array}{c}\text { No signs of } \\
\text { deviant } \\
\text { affiliation } \\
(1-5)\end{array}$ & \begin{tabular}{|c|} 
Positive \\
family \\
socialization \\
$(1-5)$
\end{tabular} & $\begin{array}{c}\text { No signs of } \\
\text { structural } \\
\text { strains } \\
(1-5)\end{array}$ & \begin{tabular}{|c|} 
Child friendly \\
school \\
environment \\
$(1-5)$
\end{tabular} & & \\
\hline \multirow[t]{8}{*}{1} & 2 & 3 & 4 & 5 & 6 & 7 & 8 & 9 & 10 & 11 \\
\hline & Child_1 & & & & & & & & & \\
\hline & Child_2 & & & & & & & & & \\
\hline & Child_3 & & & & & & & & & \\
\hline & Child_4 & & & & & & & & & \\
\hline & Child_5 & & & & & & & & & \\
\hline & Child_6 & & & & & & & & & \\
\hline & Child .......(n) & & & & & & & & & \\
\hline
\end{tabular}

Rating interpretation: If the total score in column ' 10 ' is:-

$\checkmark$ between 7 to 21 , means "needs urgent attention" - Give rating 'Red'

$\checkmark$ between 22 to 27 , means "currently satisfactory, but needs attention" - Give rating "Yellow'

$\checkmark$ between 28 to 35, means "maintain its current status" - Give rating 'Green'

Interventions for preventing and protecting children from dropping out of school:-

Based on the table 2 summary scores, strategic interventions could be designed, which should be fully contextualized to local situation. The strategic framework for social protection by UNICEF states that equitable and inclusive education systems depend on both demand- and supply-side interventions. On the one hand, appropriate infrastructure, socio-culturally pertinent systems and quality of services are at the core of education service delivery. On the other, financial and social barriers to access to education services are key factors in determining education outcomes. The findings of school dropout study conducted by the author also reflected the same.

The Right of Children to Free and Compulsory Education Act 2010, aims for all children to be in school and learning from 3 years to 18 years, more specifically from 6 to 14 years. In other words, children are entitled for basic minimum standard of education, free of costs, for realising their full potential and should not be biased on gender, socio-economic status, religious background or ethnicity. The researcher suggests to have equity strategies to ensure the right of children to access fair and inclusive education systems. 
The following are the six pronged strategies and interventions to address school dropouts:

Promote child friendly schools and improve learnings:-

By conducting periodic public hearings and using the findings to strengthen the RTE act to ensure quality elementary education to all children in a child friendly and child centric environment to ensure learning.

Using dropout prediction framework and scoring technique (table 2), identify children who are at 'high risk - Red colour' to school dropout and track them through the decisions, events and interactions could provide valuable insights to support them to remain enrolled and attending, as well as provide learning pointers on what are the tipping points and how these might be managed. Also develop child specific action plan for preventive and protective measures towards school dropouts.

Ensure all children in school up to secondary level:-

Using community mobilization as a vehicle to improve preparedness for schooling depends on how children are getting an early start and readiness in learning at the early childhood centers. Hence, strengthening the early childhood care and education (ECCE) shall support the retention and improved learning of the children.

\section{Improve parent-teacher relationships and parent's involvement:-}

Strengthening of soft skills of teacher as well as parent's involvement mechanisms in the school. This will improve quality interactions.

\section{Empowering community for demanding quality education and to promote equity:-}

The effort to welcome children from diverse and socially vulnerable groups to school and to encourage learning can be more effectively directed at community level. Strengthening School Management Committee (SMC) is absolutely crucial at this juncture. Effective social and behaviour change methods to be used for empowering community to remove and fight against the vile of gender specific inequalities, early marriage, and support system for children of distress migrants, child labour, delinquency behaviour.

Increasing the coverage of social protection programmes:-

As observed in the study, any social protection mechanisms provides support/ relief to the children. Through an integrated multi-sectoral approach, well-functioning social protection systems can contribute to addressing many of the underlying causes of increased risk and vulnerabilities.

\section{Conclusion:-}

The inspired ambition for children is to flourish in a child-friendly learning and home environment with strong school, family and community based structures. However, it depends on the degree of aspirations of the parents, their socio-economic-demographic and the children who can play a strong role to achieve their ambition for educational fulfilment. Regardless of various footsteps undertaken by the education department, school dropouts is still widely acknowledged discussion topic in the education sector.

Based on the field experiences, author has designed and developed result framework, comprehensive school dropout prediction framework, and prediction instrument and prevention strategies. It is expected that this paper would be useful to policy makers to empower school management committee and class teacher to use and predict possibilities of school dropouts in their classes and reinforce to develop child specific plan of action for ensuring accomplishment of schooling up to secondary level. It is recommended to design series of robust programs to tap capacity gaps among children, families, communities, school functionaries and district officials and help them to improve individual and collective behavioral issues and performance at the institutional level.

\section{Acknowledgements:-}

I would like to acknowledge the support and guidance being provided by Dr. D.K. Lal Das, Principal (Retired), Roda Mistry College of Social Work, Hyderabad and Prof. Mani Shankar Joshi, Dean, Faculty of Education and Arts, Jodhpur National University as supervisors to my PhD thesis. 


\section{References:-}

1. Akanle, O.B. (2007). Socio-economic factors influencing students' academic performance in Nigeria. Some explanation from a local survey. Sociology and social work community. Free online library.

2. Dey, Deepak Kumar (2016). Processes on how decisions are made and why around drops outs - A case study of School Dropouts in Mahbubnagar district of Telangana State, India. World Journal of Educational Research. Vol. 3, No. 3, Pp.1-9.

3. Dey, Deepak Kumar (2016). The nature and extent of parent's attitude towards school dropouts. Imperial Journal of Interdisciplinary Research (IJIR). Vol-2, Issues 7. Pp 1690-1695.

4. Dey, Deepak Kumar (2016). Nature and extent of factors influencing delinquency and peer group influence to school dropouts, International Journal of Modern Sciences and Engineering Technology vol-3, Issue 6. Pp. 1018.

5. Dey, Deepak Kumar (2016). The causative factors of school dropouts. Imperial Journal of Interdisciplinary Research (IJIR). Vol-2, Issues 8. Pg. 655-666.

6. District Information System of Education (DISE) 2013-14, NUEPA, New Delhi

7. Eccles, J.S., and Harold, R.D. (1993). Parent-school involvement during the early adolescent years, Teachers college record, 94, 568-587.

8. Epstein, J.L.,\& Connors, L.J.(1994). School, family, and community partnerships in high schools (Report No. 24). Baltimore: Johns Hopkins University, Center on Families, Communities, Schools and Children's learning.

9. Kroth, R. (1981). Involvement with Parents of Behaviorally disordered Adolescents. 